\title{
Centralization or Decentralization? The Future of Global Climate Governance
}

\author{
YuJia Ren
}

Nagoya University

Email: renyujia0207@163.com

\begin{abstract}
Compared with other global issues, climate change is relatively slow yet its consequences have spread throughout ages. To migrate and adapt climate change, a series of efforts and arrangements have been made. However, the proliferation of institutional arrangements regulating climate change has resulted in a fragmentation and decentralization of climate governance. Whether centralization or decentralization would be more effective for future climate governance is a heat topic discussed by scholars. This paper argues that institutional fragmentation could contribute to the effectiveness of climate governance in the short term, as fragmented institutions could facilitate faster agreement and promote the participation of emerging powers.
\end{abstract}

Keywords: Climate Change, Global Governance, Fragmentation, Centralization, Regime Complex

\section{INTRODUCTION}

Existing literature shows that the international community has been pursuing centralized governance mechanisms in dealing with global issues. However, with the deepening of globalization, the issues, actors and international mechanisms have diversified. Many areas, such as trade, environment, and poverty, have shown a trend of fragmentation of mechanisms in governance, among which the fragmentation of climate governance mechanisms is particularly remarkable.

The aim of this paper is to gain a deeper understanding of the phenomenon of fragmentation and thus to correct some perceptions of global climate governance, such as the obsessive pursuit of a unified and centralized mechanism for climate governance and the negotiations within the UNFCCC. And if China wants to continue to play a role in global climate governance in the future, whether it is possible to establish a China-lead rule-making mechanism to participate in climate governance requires a deep understanding of what fragmentation really is.

\subsection{Research Question}

Since the 1970s, the climate issue has become active in the international political arena, and because of its complexity and connection with many issues, it has become one of the major challenges for the international community. The United Nations Framework Convention on Climate Change (UNFCCC), adopted at the United Nations Conference on Environment and Development (UNCED) in 1992, and its subsequent Kyoto Protocol is the main regime for climate governance. However, due to the ineffectiveness of the UN-led climate governance regime, many multilateral institutions have also begun to address climate change issues. For example, the Group of Twenty (G20) has included climate change and energy efficiency as important issues, and discussed them at its leaders' summits, making a series of commitments related to climate change mitigation and adaptation. Non-state actors such as NGOs, corporations, and individuals are also involved in the process of global climate governance. It is obvious that the climate governance is now showing a trend of fragmentation. ${ }^{[1]}$

Even though the international community has sought to establish a centralized global regime, it seems that more and more fragmented regimes or institutions have already emerged. Would it be better for climate governance to continue to pursue a centralized governance regime or could such fragmentation be in fact a symbol of effectiveness instead of chaos?

\subsection{Method and Material}

This paper selects the actions and efforts made by 
the international community in the climate area as cases to reflect to the governance dilemma and the contradiction between the actors of governance. At the same time, the fragmentation theory is sorted out based on a detailed analysis of the literature. Since the perspectives and opinions on global governance fragmentation are diverse, this paper examine those perspectives which is powerful on explaining the reality of the climate governance.

Using climate governance as a case, this paper sorts out the existing regime and institutions in the field of climate governance through extensive textual analysis. The cooperative fragmentation that currently characterizes climate governance inspires me to explore the positive theoretical implications of fragmentation.

At the same time, I also notice the characteristic of conflictive fragmentation in climate governance, such as disagreements among member states within the UNFCCC, which inspires me to explore whether a centralized regime will hinder the development of climate governance instead.

\section{THE OLD OPINION: THREE TYPES OF FRAGMENTATION}

\subsection{Definition of Fragmentation}

In order to study the potential logic of the evolution of fragmentation of climate governance, it is necessary to review the definition of fragmentation and analysis its causes. At the beginning of the 21 st century, scholars of international relations began to study and discuss the phenomenon of fragmentation. Frank Biermann and his colleges argue that the fragmentation is inevitable due to 'a patchwork of international institutions that are different in their character (organizations, regimes, and implicit norms), their constituencies (public and private), their spatial scope (from bilateral to global), and their subject matter'. [2] They thought that the involvement of a large number of public and private actors has led to the emergence of more bilateral and multilateral governance mechanisms, formal or informal, than just a single global mechanism. Fariborz Zelli and Harro van Asselt followed Biermann's explanation, considering fragmentation as the challenge of public and private norms, and diversity of treaties in the field of international politics. ${ }^{[3]}$

\subsection{Factors of Fragmentation}

Tana Johnson identifies five factors that could explain the trend of institutional fragmentation: transaction costs, complexity, distributional conflict, enforcement, and individual leadership. In detail, high transaction costs impede the trend toward regime integration and increase the prospect of regime separation. The externalities of public issues, resulting in spillover crossover between different issues and a highly complex and intertwined web of relationships, combined with the uneven distribution of state interests in governance cooperation, further contribute to fragmentation. Fragmentation is also likely to be exacerbated by the lack of effectiveness resulting from the implementation of agreements formed by regimes that do not meet expectations. In addition, fragmentation can be influenced by the behavioral preferences of decision makers at the individual level. ${ }^{[4]}$ In the field of climate governance, Keohane and Victor propose the distribution of interests, uncertainty, and linkages as three factors helping explain the fragmentation of climate governance. ${ }^{[5]}$ For example, the disagreement between the U.S. and the EU on the Kyoto Protocol and the diverse interests of developed and developing countries have led to the fragmentation of climate regime preferences. Meanwhile, due to the high compliance costs, countries are reluctant to accept comprehensive climate agreements that require practical actions without certainty about future benefits and whether other countries will fulfill their emission reduction commitments. Moreover, because of the diversity of issues related to climate change, a number of different institutional designs have been used to enhance issue linkages. Policy decisions made out of consideration of institutional linkages have also led to institutional fragmentation. These three causes, combined with the diversity of the specific cooperation problems inherent in the challenge of "climate change" and the political difficulties to implement carbon mitigation measures, have led to institutional fragmentation in the climate field. ${ }^{[6]}$

In global environmental politics, numerous multilateral agreements and treaties have been signed and entered into force. How to address such fragmentation is a central issue for future climate governance. Some scholars have proposed strengthening the convergence of environmental institutions and establishing a world environmental organization to reduce the trend of fragmentation and decentralization in this field and to create a complete institutional structure in the field. For example, Biermann has suggested that an integrated world environmental organization could better coordinate global environmental governance, allowing for stronger linkages across environmental issue areas and the formation of uniform standards and norms. ${ }^{[7]}$ On the contrary, others argue that fragmentation could instead bring certain benefits. Keohane and Victor argue that in the climate field, fragmented institutions and regimes form a regime complex, and the regime complex is instead characterized as flexibility and adaptability compared to an integrated, unified mechanism, which helps break the deadlock of climate governance. 


\subsection{Types of Fragmentation}

According to Biermann, institutional fragmentation could be sorted into three different types based on institutional integration, normative conflict, and actor structure: synergistic fragmentation, cooperative fragmentation, and conflictive fragmentation. ${ }^{[8]}$ Among them, synergistic fragmentation refers to the existence of a core mechanism that encompasses most members and provides effective, detailed universal principles in a clear, ongoing, holistic institutional arrangement. Cooperative fragmentation is where the problem area is broadly defined by different mechanisms or by the decision-making process, where the relationship between the norms and principles of different mechanisms under the same problem is ambiguous, and where the core mechanism does not encompass all the important countries under this problem area. Conflictive fragmentation refers to the fact that these mechanisms have different policy decision-making processes and that the different decision-making processes are difficult to relate to each other or even conflict in terms of principles, norms and rules. Meanwhile, Biermann argued that climate governance mechanisms have elements of all three types of fragmentation at the same time. As the core of the climate governance regime, UNFCCC defines many of the fundamental principles in this area and provides a relatively well-established international regime, suggesting that the core of the climate governance architecture is characterized by synergistic fragmentation. Yet, climate governance is also characterized by cooperative fragmentation. Besides the UN climate regime, there is a growing array of formal and informal governance institutions and agreements at different levels that are linked to the UN regime through their participation in multilateral forums. Most of the institutional governance arrangements recognize the legitimacy and authority of the UN mechanisms. Whereas, the U.S.-led Asia-Pacific Partnership on Clean Development and Climate (APP) and the Major Economies Conference on Energy Security and Climate Change (MEC) both exhibit an ambition of separation from the UN mechanisms, which in turn suggests conflictive fragmentation of climate governance.

\section{NEW QUESTION AND POSSIBILITY}

\subsection{The Fragmented Climate Governance}

If the climate governance architecture shows indications of all three types of fragmentation, is it better to retain a fragmented governance architecture that is more conducive to climate problem solving, or is a centralized regime more appropriate for climate governance to evolve? We need to analyze the dominant regimes of climate governance.
Although the international community has been striving to establish a centralized climate governance regime under the framework of the UNFCCC, the complexity of the climate issue makes the single mechanism established by the UN untenable. The two major issues in the climate negotiations, one is how to reduce greenhouse gas emissions in developed countries, and the other is how to help developing countries resolve the contradiction between environment and development. Eventually these gaps have resulted in the breakdown of the negotiating camps and even the formation of rival cliques. ${ }^{[9]}$ The deadlock of the climate negotiation has weakened influence of the UNFCCC, and this formal regime faces the challenge of being marginalized. Also, more and more evidence shows that while there has been little progress in comprehensive negotiations, there is a growing number of informal institutions. For example, a broad coalition of developing countries, the "Group of Seventy-Seven" and China, united by a desire to confront the injustices of the developed world, are working in small groups outside the UNFCCC process. It is easy to see that the institutional fragmentation does in some ways facilitate the development of climate governance. Fragmented institutions enable actors to choose where and how to engage. ${ }^{[10]}$ Such forum shopping allows actors to choose institutions that are similar to their own interest preferences to participate in climate governance actions, and to a certain extent can expand the number of actors involved in climate action. Compared with the slow process of climate negotiations under the UN framework, informal institutions can reach climate cooperation agreements and address climate change challenges more quickly due to the small number of actors involved. In addition, decentralized institutions with specialized expertise can facilitate cooperation on a specific issue, and inter-institutions can also promote bottom-up coordination through linkages between issues. The G20, along with OECD and IEA, have promoted consensus on climate action among countries through linkages between issues such as climate finance and energy and climate change, and have also laid the foundation for cooperation under the UNFCCC framework.

Although the Paris agreement defines a relatively flexible global governance system for emission reduction, divergent interests among countries on the issue of emission reduction still exist. This fundamentally also makes it difficult to establish a centralized climate cooperation regime. At the same time, the cooperative fragmentation that has emerged in the climate governance arena instead offers cross-issue flexibility and adaptability over time. If governments and non-state actors are strategically seeking more effective climate change management, they could turn to fragmented institutions to their advantage. Continuing to seek to establish a centralized climate regime may no 
longer be a good solution, and it is time to consider how to manage the fragmented institutions to achieve climate cooperation.

The climate governance regime is indeed moving further toward cooperative fragmentation. Although the Convention provides basic norms for multiple governance actors, its role is very limited and its capacity of coordination is slightly inadequate due to the lack of a complete organizational framework and decision-making mechanism. Although most of the institutions outside of the UNFCCC have crossed and overlapped functions, cooperation among institutions has also emerged, with the G8/G20 as the hub of the network. In addition, the conflict embodied in the U.S.-led APP and MEF reflects the most serious disagreement in the field of climate governance, which is the conflict of interest and power game among countries. This is a serious challenge that has always existed in climate governance, and a key reason why climate governance has frequently come to a deadlock. It is quite often to see that national actors clash or compete on international issues for their own interests. In global climate governance, how to provide a norm for this conflict of interest and power play to avoid vicious competition so that it cannot undermine climate governance is the real question raised by the fragmentation of global climate governance.

\subsection{Fragmentation or Centralization}

Some criteria are given to answer the question of whether to change the status quo of fragmentation or what should be changed is just our perception of fragmentation from a phenomenon that needs to be changed to a normal one. Existing researches on whether it is more beneficial to choose centralization or fragmentation provide six criteria for consideration.

First, a centralized, powerful architecture is likely to be more influential against competing international organizations and with constituent states. ${ }^{[11]}$ In the area of global trade, for example, the WTO sets strong enforcement norms and can even change the actions of member states based on WTO rules. In the environmental field, however, the United Nations Environment Programme and various multilateral treaties have been criticized for not having strong rules and influence. Second, a centralized architecture is better for saving costs and simplifying participation. Decentralized governance instead tends to create overlapping bodies, and the hundreds of international environmental treaties have created what is known as "treaty congestion" ${ }^{[12]}$ and a large number of secretariats with similar functions. This forces countries to spread resources and funding among different bodies, thus limiting participation by countries with less capacity and resources. ${ }^{[13]}$
Third, the problem with centralization is that the process of building a centralized system is slow, especially in issue areas that require high levels of participation. But the international situation is always changing rapidly, and the speed of establishing centralized regimes often does not keep up with international changes. In the case of fragmented institutions, however, the presence of many informal institutions often allows for a timely response to international crises. In addition, well established centralized regimes still suffer from vulnerability. Centralized regimes are vulnerable to regulatory capture and manipulation by interest groups. And because international institutions tend to be path-dependent, a centralized architecture tends to be more difficult to respond to a volatile international environment. ${ }^{[14]}$ Fourth, centralization may be in a dilemma between pursuing higher participation and setting stricter targets. Centralized regimes tend to require strong commitments from countries and thus limit participation. ${ }^{[15]}$ But sacrificing stricter normative goals in exchange for more country participation can sometimes create risks. But fragmentation might make some major powers willing to engage in the regulatory process.

Fifth, fragmentation would allow actors to choose where and how to participate. Such 'forum shopping' may take one of several forms: shifting venues, abandoning one, creating new venues, and working to sew competition among multiple. ${ }^{[16]}$ But it is uncertain whether this forum shopping will help or hinder governance. Sixth, both centralization and fragmentation promote policy coordination in different forms. Centralized regimes can provide a focal point for actors and facilitate communication among them yet fragmented institutions can also ensure bottom-up coordination through linkages between them. Some proponents of decentralized polycentric governance argue that the invisible hand of institutional markets allows for a better distribution of functions and effects. ${ }^{[17]}$

\section{CONCLUSION}

This paper analyzes whether the fragmentation of global climate regime has positive implications for climate governance. In terms of theoretical significance, it serves to further understanding of global governance and helps to correct the negative perception of fragmentation in the academic community. This research may shift the academic discussion from how to avoid decentralization to how to effectively manage the development of fragmentation to make it more beneficial to climate governance. In practical terms, studying the positive aspects of fragmentation will help countries that are committed to or want to engage in climate governance to better understand the current 
situation of climate governance and to choose a regime or institution that suits their conditions.

In the long term of interests, the fragmentation of climate governance may be the institutional weakness that prevents a systematic solution to the climate crisis. However, this paper argues that institutional fragmentation can contribute to the effectiveness of climate governance in the short term. On the one hand, fragmented institutions facilitate faster agreement. For example, at the Hamburg Summit in 2017, the G20 responded quickly to the Paris Agreement by developing and adopting the G20 Hamburg Climate and Energy Action Plan. On the other hand, the institutional fragmentation is conducive to the participation of emerging powers and the promotion of climate governance. Emerging powers, such as the BASIC countries, have emerged as a significant force in global climate politics since Copenhagen in 2009, and since most of their member countries overlap with the BRICS, the BRICS platform has also started to frequently update its agenda on climate change. At the same time, emerging powers are using the G20 platform to engage in climate negotiations with traditional developed country groups outside the UNFCCC.

As we analyzed before, climate governance is characterized by cooperative fragmentation, but also contains conflictive characteristics. This paper argues that since it is very difficult to establish a highly integrated climate governance regime, it is crucial to intervene in the construction of the regimes to avoid their excessive development toward conflictive fragmentation. It is politically feasible to strengthen the synergy between the UN climate regime, including the UNFCCC and a series of climate agreements concluded under it, and flexible informal institutions to promote the benign development of the regime complex of climate change.

\section{REFERENCES}

[1] For details, see Van Asselt, H. (2007). Dealing with the Fragmentation of Global Climate Governance: Legal and Political Approaches in Interplay Management. Legal and Political Approaches in Interplay Management. Global Governance Working Paper No.30; Biermann, F., Pattberg, P., van Asselt, H., \& Zelli, F. (2009). The Fragmentation of Global Governance Architectures: A Framework for Analysis. Global Environmental Politics, 4, 14-40; Orsini, A. (2013). Multi-Forum Non-State Actors: Navigating the Regime Complexes for Forestry and Genetic Resources. Global Environmental Politics, 3, pp.34-55; Orsini, A., Morin, J. and Young, O. (2013). Regime Complexes: A Buzz, a Boom, or a Boost for Global Governance? Global Governance:
A Review of Multilateralism and International Organizations, 19(1), pp.27-39; Struett, M. J., Nance, M. T., \& Armstrong, D. (2013). Navigating the Maritime Piracy Regime Complex. Global Governance: A Review of Multilateralism and International Organizations, 1, pp.93-104; Margulis, M. E. (2013). The Regime Complex for Food Security: Implications for the Global Hunger Challenge. Global Governance: A Review of Multilateralism and International Organizations, 1, pp.53-67.

[2] Biermann, F., Pattberg, P., van Asselt, H., \& Zelli, F. (2009). The Fragmentation of Global Governance Architectures: A Framework for Analysis. Global Environmental Politics, 4, 14-40.

[3] Zelli, F., \& van Asselt, H. (2013). Introduction: The Institutional Fragmentation of Global Environmental Governance: Causes, Consequences, and Responses. Global Environmental Politics, 3, pp. 1-13.

[4] Johnson, T., \& Urpelainen, J. (2012). A Strategic Theory of Regime Integration and Separation. International Organization, 4, 645-677.

[5] Keohane, R. O., \& Victor, D. G. (2011). The Regime Complex for Climate Change. Social Science Electronic Publishing, 9(1), 7-23.

[6] Same as [5]

[7] Biermann, F. (2000). The Case for a World Environment Organization. Environment Science \& Policy for Sustainable Development, 42(9), 22-31.

[8] Same as [2]

[9] Narain, S. (2012). The poor against the poor on climate. Business Standard.

[10] Cihon, P., Kemp, L., \& Maas, M. (2020). Fragmentation and the Future: Investigating Architectures for International AI Governance. Social Science Electronic Publishing,11(5), 545-556.

[11] Orsini, A., Morin, J. and Young, O. (2013). Regime Complexes: A Buzz, a Boom, or a Boost for Global Governance? Global Governance: A Review of Multilateralism and International Organizations, 19(1), pp.27-39.

[12] Anton, D. (2012). 'Treaty Congestion' in International Environmental Law, in S. Alam, J. H. Bhuiyan, T. M. Chowdhury and E. J. Techera, eds, Routledge Handbook of International Environmental Law, Routledge, pp.651-66.

[13] Esty, D. and Ivanova, M. (2002). Revitalizing Global Environmental Governance: A 
Function-Driven Approach, in D. C. Esty and M. H. Ivanova, eds, Global Environmental Governance: Options \& Opportunities, Yale School of Forestry and Environmental Studies.; Brockmann, K. (2019). Challenges to Multilateral Export Controls, Stockholm International Peace Research Institute; Morin, J., Dobson, H., Peacock, C., et al. (2019). How Informality Can Address Emerging Issues: Making the Most of the G7, Global Policy, 10(2), pp.267-273.

[14] Picker, C. (2001). A View from 40,000 Feet: International Law and the Invisible Hand of Technology, Cardozo Law Review, 23, pp.151-219; Alter, Karen J., and Raustiala, K.
(2018). The Rise of International Regime Complexity. Annual Review of Law and Social Science, 14(1), pp.329-49.

[15] Kemp, L. (2017). US-proofing the Paris Climate Agreement', Climate Policy, 17(1), pp.86-101; Zelli, F. (2011). The fragmentation of the global climate governance architecture, Wiley Interdisciplinary Reviews: Climate Change, 2(2), pp.255-270.

[16] Braithwaite, J., \& Drahos, P. (2000). Global Business Regulation. Cambridge University Press.

[17] Same as [3] 